\title{
Can Vertical GPS Displacements Serve As Proxies for Climate Variability in North America?
}

\author{
Shimon Wdowinski (i) and Tonie M. van Dam (i)
}

\begin{abstract}
Vertical crustal displacements induced by atmospheric, hydrological, cryospheric, and oceanic load changes are detectable with sub-cm accuracy by precise continuous GPS measurements. Areas subjected to rapid load changes due to ice sheet melt, drought, massive groundwater extraction, or lake level drop, are characterized by a dominant non-linear vertical signal. Here, we investigate possible relations between vertical crustal movements and climate change by analyzing the relations between observed GPS vertical movements, predicted movements, and climatic indices, where we have long GPS time series ( $>20$ years). Applying our analysis to GPS records from western and eastern North America indicates different load change characteristics. In the western US, the seasonal and climatic signals are dominated by hydrological load changes and, consequently, the GPS signal correlates well with the Palmer Severe Drought Index (PSDI) calculated for the same region. However, vertical crustal movements in eastern North America, as detected by long GPS time series, reveal poor correlation with PSDI and other climatic indices. Our results suggest that long continuous GPS observations of vertical crustal displacements primarily driven by climate related changes in water storage can serve as independent measures of regional-scale climate change in some cases, mainly in western north America.
\end{abstract}

\section{Keywords}

Climate indices · Crustal deformation · GPS · GRACE · Palmer Severe Drought Index

\section{$1 \quad$ Introduction}

Displacement of the Earth's crust, mostly in the vertical direction, occurs in response to load changes induced by the atmosphere, hydrosphere, and cryosphere; these components of the Earth system are affected by climate change. The largest load changes occur by sediment deposition and the melting of thick ice sheets and results in tens or even hundreds of meters of vertical crustal movements over periods

S. Wdowinski $(\square)$

Department of Earth and Environment, Florida International

University, Miami, FL, USA

e-mail: shimon.wdowinski@ fiu.edu

T. M. van Dam

Université du Luxembourg, Esch-sur-Alzette, Luxembourg of thousands of years, as recorded by uplifted shorelines in Fenoscandia and in other near polar regions (Mörner 1979). Smaller load changes induce smaller movements, which are measured nowadays using space geodetic techniques, mainly GPS and InSAR, with sub-cm accuracy level (Wdowinski and Eriksson 2009). GPS observations in Greenland and the northern Atlantic regions revealed non-linear rates of crustal uplift, reflecting the accelerating rate of ice mass loss in the region in response to the changing climate (Jiang et al. 2010; Bevis et al. 2012). Similarly, GPS observations in the western US, mainly in California, detected transient crustal movements, reflecting crustal response to changes in the hydrological load due to changing lake levels, groundwater depletion, and the California drought (Amos et al. 2014; Brosa et al. 2014; Wahr et al. 2013; Hammond et al. 2016). The above two examples demonstrate that observations of the GPS vertical component can be used as a proxy for 
climate variability as it indirectly observes hydrological and cryospheric mass changes.

Crustal deformation in response to load change has extensively studied using elastic deformation with both forward and inverse modeling techniques (e.g., Davis et al. 2004; van Dam et al. 2007). In particular, studies of hydrological load change found that vertical GPS movements have a capability for estimating changes in terrestrial water content (TWC) changes through inversion of vertical deformation (e.g., Tregoning et al. 2009; Fu et al. 2012). The application of GPS vertical movements for TWC estimation was verified mostly in western North America by comparing the GPS observations to predicted movements derived from hydrological load models and GRACE observations. However, it is not clear if GPS vertical movements can be used for estimating TWC changes in other regions, such as eastern North America.

In this study we hypothesize that vertical crustal movements recorded by long continuous GPS time series ( $>20$ years) can provide an independent measure of climate variability. If so, our study will provide an insight into the sustainability of geodetic reference frames, as climate change progresses. The rational for the hypothesis is the observed crustal response to hydrological load changes, as presented above. Thus, our first attempt is to compare vertical GPS movements with hydrological climate indices, as the Palmer Drought Severity Index (PDSI; Alley 1984). We also compare the observed GPS movements with predicted movements calculated from modeling the crustal response to hydrologic load changes, based on both a hydrological model and GRACE observations. Our results indicate that vertical GPS movements correlate with the predicated hydrological load and PDSI mainly in the western North America. In locations where vertical GPS movements do not correlate well with PDSI, mainly in eastern North America, we explore possible correlations with other climate indices, such as the North Atlantic Oscillation (NAO). However, our results indicate poor correlation with these indices, suggesting that vertical GPS time series have only a limited sensitivity to climate change.

\section{Data}

Our study relies on multiple data types, as we seek to find casual relations between vertical crustal movements, hydrological load estimates, and climate indices. The vertical crustal movements are determined from long continuous GPS time series. In this study, we use daily solutions provided by the Nevada Geodetic Lab (NGL - http://geodesy. unr.edu/) in the IGS08 reference frame. NGL also provides solutions in the NA12 reference frame; however, in these solutions a significant part of the hydrological signal is removed due to the continental scale spatial filtering (Blewitt et al. 2013).

The hydrological load estimates are calculated based on the Global Land Data Assimilation System (GLDAS; Rodell et al. 2004) and GRACE gravity field observations. We did not include atmospheric and non-tidal load calculations, as these loads are significantly small when compared with the amplitude of the hydrological loading signal. We also used time series of climate indices as provided by the National Oceanic and Atmospheric Administration (NOAA). We used PDSI values of the sub-state divisions, according to the locations of the selected GPS stations, which are available at https://www.ncdc.noaa.gov/cag/divisional/timeseries. We also used time series of the North Atlantic Oscillation (NAO), Atlantic Multidecadal Oscillation (AMO), and El Niño/Southern Oscillation (ENSO). All indices are provided by NOAA at https://www.esrl.noaa.gov/psd/data/ climateindices/list/.

\section{Methodology}

The main tool for testing our hypothesis is to conduct a systematic comparison between time series of vertical GPS movements, predicted crustal movements due to hydrologic load changes, and climate indices. Before conducting such a comparison, we need first to select suitable GPS records for the analysis and also compute the predicted movements for the same locations using GLDAS model results and GRACE observations. The GPS site selection was based on the following three criteria: The site (1) must be located in North America $\left[25-55^{\circ} \mathrm{N} ; 50-130^{\circ} \mathrm{W}\right]$; (2) have a time series with a time span longer than 20 years; and (3) have at least 6,000 daily solutions. Based on these criteria, we found a total of 177 stations (Fig. 1). However, many of these time series contain steps and transient behavior, which most likely represent artifacts due to equipment/firmware change, co-seismic displacements, and other unexplained behavior. Using timing of offsets provided by NGL, we corrected the time series for the noted offsets. Unreported offsets where detected and corrected using a best-fit step function algorithm. After time series cleaning, we found that only $87 \%$ (155 stations) have periods without unusual behavior (strange transients) that can be used in the comparison. Additional pre-comparison processing includes detrending the series, as some, especially those in northern latitudes, contain a significant trend (up to $4 \mathrm{~mm} /$ year) reflecting crustal response to Glacial Isostatic Adjustment in this region.

For the selected 155 GPS stations, we predicted crustal movements due to hydrological load changes using GLDAS and GRACE observations. The GLDAS water storage loads were obtain from the GLDAS website (https://ldas.gsfc.nasa. 


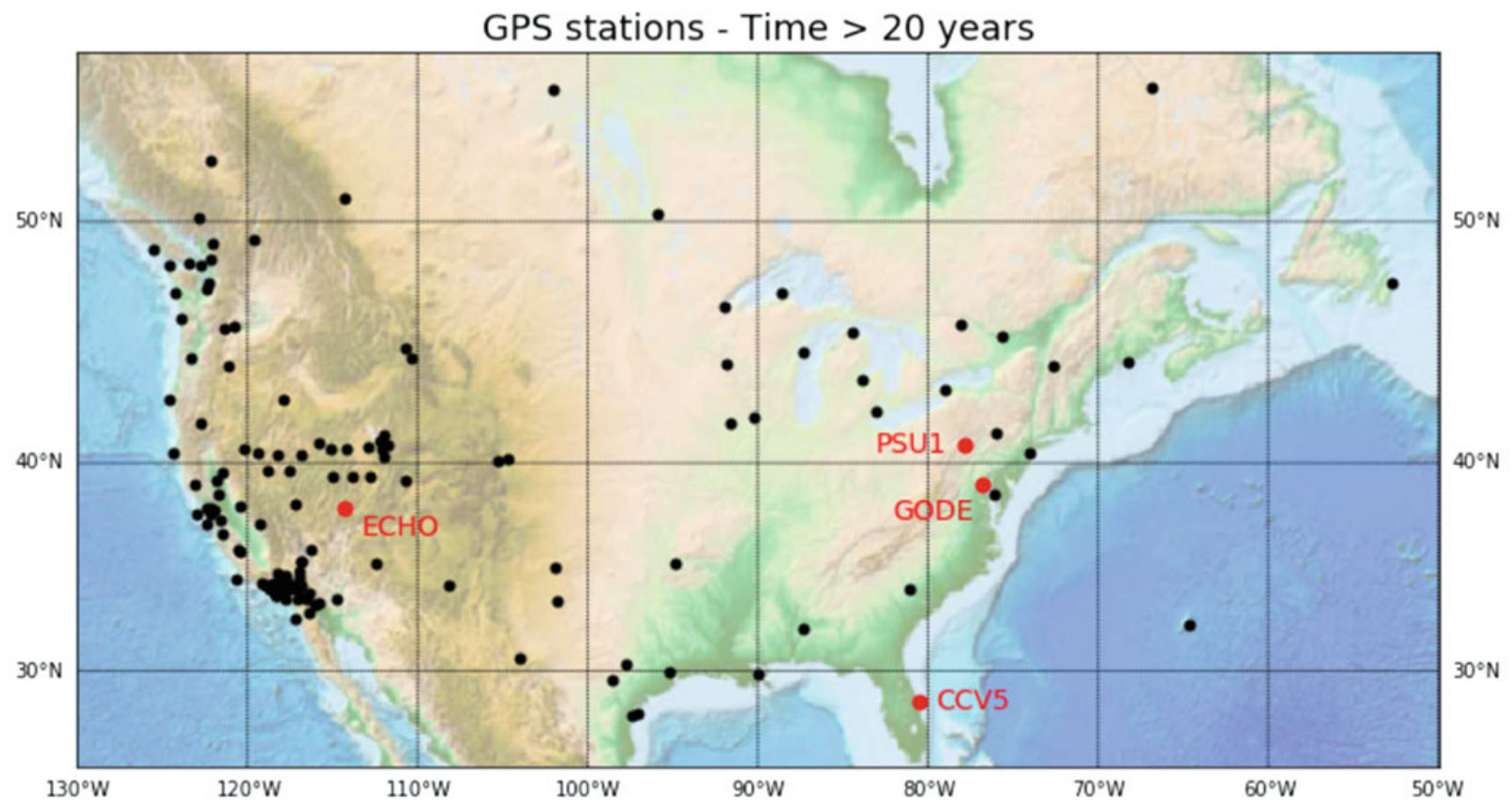

Fig. 1 Location map of GPS station in north America with continuous data acquired over a period of more than 20 years. Red circles and text mark the location of the four GPS time series presented in this study

gov/gldas), which provides water storage values comprised of soil moisture, canopy water, and snow water equivalent with a spatial resolution of one degree grid spacing at monthly intervals. The GRACE-derived load changes were determined by convolving the gravity field coefficients with load Love numbers (in the CF reference frame defined by the GPS). The GRACE data are the CSR R05 products. GRACE C20 is replaced with the C20 determined from SLR. Degree-1 is restored to the spherical harmonic files. The data are then destriped (Swenson and Wahr 2006) and subsequently filtered with a $350 \mathrm{~km}$ Gaussian averaging kernel. High frequency atmospheric and oceanic de-aliasing products were added back into the gravity fields. For the GLDAS data, we estimated the crustal response to loading by converting the water equivalent values to surface mass and then convolving them with Farrell's (1972) Green's functions (Gutenberg-Bullen B Earth model) that have been converted into to a center of figure frame. This reference frame is consistent with the frame that is estimated by GPS time series that have been transformed into a reference frame such as IGS08.

The comparisons between time series of vertical GPS movements, predicted crustal movements due to hydrologic load changes, and climate indices are conducted both visually and quantitatively. The visual comparison is conducted by using smooth curves through the time series data point based on a lowpass filter with 0.5 -year cutoff, which accounts for multi-year and seasonal variations, but not daily changes. The daily values have much more variability and are considered as measurement noise. The quantitative comparison is conducted using a correlation analyses of mean monthly values, which are quantified by the Pearson product-moment correlation coefficient $\left(\mathrm{R}^{2}\right)$.

\section{$4 \quad$ Results}

We analyzed vertical GPS time series of 155 sites with long continuous daily solutions ( $>20$ years) and obtained mixed results. Here we present the results of four representative sites, ECHO, PSU1, GODE, and CCV5 located in both western and eastern parts of the US (Fig. 1). We chose these four sites, as they are located in different environments and climatic conditions. ECHO is located in the Basin and Range Province in eastern Nevada at an elevation of 1,684 m and subjected to semi-arid climate. PSU1 is located in an open area within the campus of Pennsylvania State University at an elevation of $311 \mathrm{~m}$ and is subjected to temperate climatic conditions. GODE is also located in an open area at elevation of $14.5 \mathrm{~m}$ in the state of Maryland, outside Washington DC, and is also subjected to temperate climate. CCV5 is located within a NASA facility in Cape Canaveral at elevation of $2 \mathrm{~m}$ and is subjected to hot and humid subtropical climate. 
Fig. 2 Time series of vertical crustal movements and the PDSI climate index for the site ECHO, located in southeastern Nevada. (a) Observed daily GPS movements (blue dots) and their smooth representation based on lowpass filter with 0.5 -year cutoff (red line). (b) Predicted monthly vertical crustal movements due to a hydrological load based on the GLDAS model (blue dots) and GRACE observations (orange dots). Continuous smooth representations of the predicted movements is shown in the solid blue (GLDAS) and cyan (GRACE) based on the same lowpass filter. (c) Calculated monthly PDSI values for western Utah (blue dots) [source: NOAA] and their smooth representation using a lowpass filter. Negative PDSI values indicate drought conditions and positive values indicate wet conditions. (d) Superposition of all four time-series used for visual comparison between the time series. The PDSI series is plotted inversely to demonstrate the inverse correlation between the climate index and the vertical crustal movements. (e) Correlation between observed monthly averaged GPS movements and predicated GLDAS movements. (f) Correlation between observed monthly averaged GPS movements and calculated PDSI values
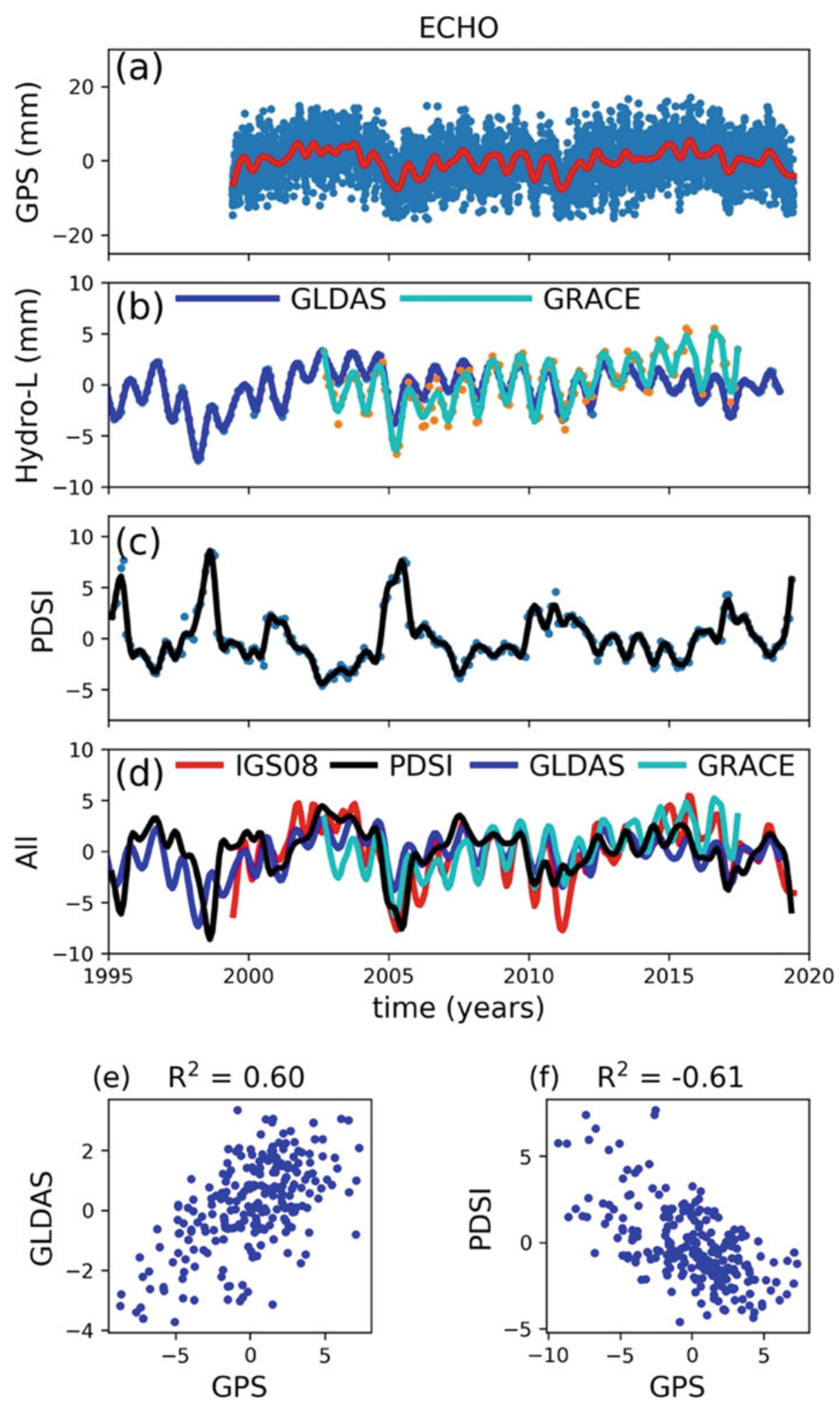

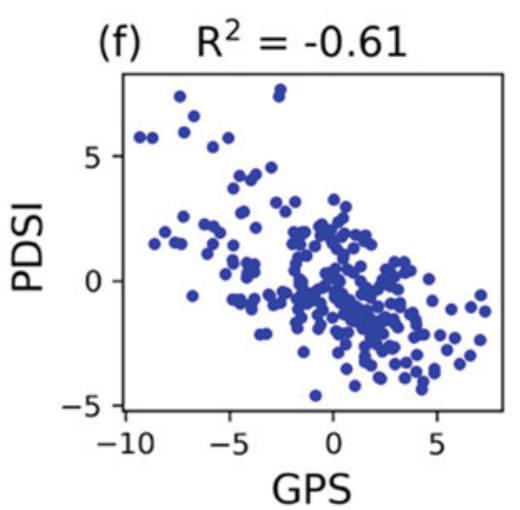

The analysis of ECHO compares time series of vertical GPS movements, predicted movements due to hydrological load changes (GLDAS and GRACE), and the PDSI for south central Nevada (Fig. 2). The GPS time series extends over a period of 20.04 years with 6,443 daily solutions, reflecting
$86 \%$ temporal coverage of the measurement period. The time series deviates within a range of $20 \mathrm{~mm}$ and contains both multi-year and seasonal periodic signals, as emphasized by the lowpass filter smooth curve (red line in Fig. 2a). The predicted movements due to hydrologic load changes by both 
Table 1 Correlation coefficient $\left(\mathrm{R}^{2}\right)$ and RMS (mm) results of correlation analyses among GPS, GLDAS, GRACE, and PDSI time series at three selected GPS station locations

\begin{tabular}{|c|c|c|c|c|c|c|c|}
\hline \multicolumn{2}{|l|}{ Site } & GPS-GLDAS & GPS-GRACE & GPS-PDSI & GLDAS-GRACE & GLDAS-PDSI & GRACE-PDSI \\
\hline \multirow[t]{2}{*}{$\mathrm{ECHO}$} & $\mathrm{R}^{2}$ & 0.60 & 0.58 & -0.61 & 0.57 & -0.56 & -0.36 \\
\hline & RMS & 2.59 & 2.77 & & 1.97 & & \\
\hline \multirow[t]{2}{*}{ PSU1 } & $\mathrm{R}^{2}$ & 0.58 & 0.54 & -0.28 & 0.80 & -0.27 & -0.11 \\
\hline & RMS & 3.01 & 3.02 & & 1.97 & & \\
\hline \multirow[t]{2}{*}{ GODE } & $\mathrm{R}^{2}$ & 0.31 & 0.20 & -0.20 & 0.81 & 0.29 & -0.17 \\
\hline & RMS & 3.76 & 4.20 & & 1.41 & & \\
\hline \multirow[t]{2}{*}{ CCV5 } & $\mathrm{R}^{2}$ & -0.22 & 0.38 & -0.20 & -0.08 & -0.04 & -0.28 \\
\hline & RMS & 4.16 & 3.81 & & 1.63 & & \\
\hline
\end{tabular}

GLDAS and GRACE are dominated by seasonal variations and some changes from one year to another (Fig. 2b). The PDSI time series is also characterized by seasonal changes and multi-year signals of long troughs (droughts - negative PDSI values) and short duration peaks (wet conditions positive PDSI). According to the PDSI time series, droughts occurred during 1996-1998, 2002-2004, 2006-2011, and 2012-2017, whereas wet conditions occurred in 1995, 1998, 2005 and 2019 (Fig. 2c). A visual comparison of all four time-series is conducted using the smooth curves of all series (Fig. 2d). The comparison shows an overall very good fit among the four series, as in the trough of 2005, but also some deviations, as the trough of 2011 where the GPS curve (red) is significantly lower than the other curves. Quantitative comparison among the time series using the Pearson productmoment correlation coefficient $\left(\mathrm{R}^{2}\right)$ reveal strong positive correlation (0.60) between the GPS and GLDAS series (Fig. $2 \mathrm{e})$ and strong negative correlation $(-0.61)$ between GPS and PDSI series (Fig. 2f). Correlation analysis among all four time-series reveal strong positive or negative correlations (0.55-0.6) except between GRACE and PDSI (-0.36) (Table 1).

The analysis of the PSU1 site is presented in Fig. 3 and Table 1. The GPS time series extends over a period of 21.58 years with 7,168 daily solutions, reflecting $91 \%$ temporal coverage of the measurement period. The analysis yields strong positive correlations among the GPS, GLDAS, and GRACE time series (0.54-0.8), but poor negative correlations with the PDSI series (0.11-0.28). The misfit between PDSI and the other series is apparent in Fig. 3d.

The analysis of the GODE data is presented in Fig. 4 and Table 1. The GPS time series extends over a period of 25.24 years with 8,302 daily solutions, reflecting $90 \%$ temporal coverage of the measurement period. The analysis yields poor correlations among the GPS, GLDAS, GRACE, and PDSI time series (0.17-0.31), except for a strong positive correlation between GLDAS and GRACE (0.8). The misfit among all series can be seen in Fig. 4d.

The analysis of the CCV5 site is presented in Fig. 5 and Table 1. The GPS time series extends over a period of 21.08 years with 6,716 daily solutions, reflecting $87 \%$ temporal coverage of the measurement period. The analysis yields poor correlations among the GPS, GLDAS, GRACE, and PDSI time series (0.4-0.28).

In sites where we found a poor fit between GPS and PDSI time series, as PSU1, GODE, and CCV5, we also conducted correlation analyses with other climate indices, including NAO, AMO, and ESNO. The rational for such a comparison is that climate patterns can affect non-hydrologic loads, such as atmospheric or non-tidal oceanic loads. However, our results yielded poor correlations between GPS time series and these other three climate indices.

The analysis of all 155 stations with long time series ( $>20$ years) revealed variable results in terms of correlations between the GPS, GLDAS, GRACE, and PDSI time series. The highest correlation levels were found among the GPSGRACE pairs, in which 88 pairs revealed moderate to high correlation level $\left(\mathrm{R}^{2}>0.4\right)$. Most of the stations with higher correlation levels are located in western North America in inland areas of high elevation (Fig. 6). The correlation level of the GPS-GLDAS and GLDAS-GRACE also showed a fairly good correlation level (60 pairs with $\mathrm{R}^{2}>0.4$ ). However, the correlation level of the PDSI climate index with GPS, GLDAS, and GRACE showed an overall poor fit level.

\section{$5 \quad$ Discussion and Conclusions}

We conducted a systematic comparison analysis among observed vertical GPS movements, predicted crustal movements due to hydrologic load changes, and climate indices, in order to test the hypothesis that vertical crustal movements recorded by long continuous GPS time series can provide an independent measure of climate change. Our analysis yielded mixed results, in which we observed good correlations between vertical GPS and PDSI time series at some sites, mainly in western north America. However, our results for eastern north America, yielded poor correlation between vertical GPS and PDSI time series. Our results for this region also yielded poor correlations between GPS and three other climate indices, NAO, AMO, and ESNO. These 
Fig. 3 Time series of vertical crustal movements and the PDSI climate index for the site PSU1, located in central Pennsylvania. Explanations for $(\mathbf{a}-\mathbf{f})$ as in Fig. 2
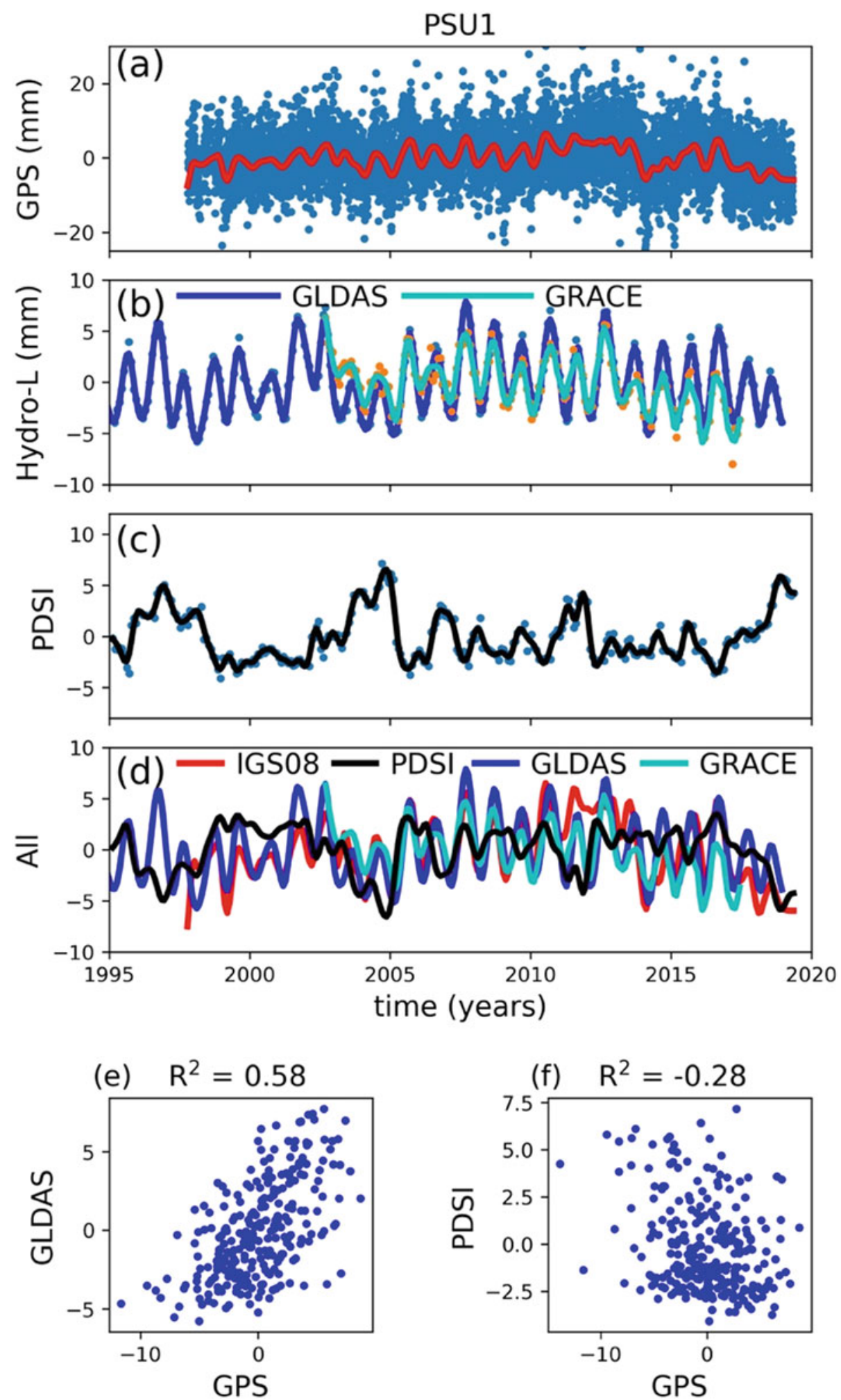

results suggested that vertical GPS time series can represent the climate signal only in some sections of north America, mainly in the mountainous western section of the continent.

We also conducted a systematic analysis between observed (GPS) and predicted (GLDAS and GRACE) vertical crustal movements due to hydrologic load changes. Our analysis yielded, again, mixed results. We found in some locations, including ECHO and PSU1, moderate correlations between the two time-series, suggesting that vertical GPS time series can serve as a good independent 
Fig. 4 Time series of vertical crustal movements and PDSI climate index for the site GODE, located in central Maryland.

Explanations for (a-f) as in Fig. 2
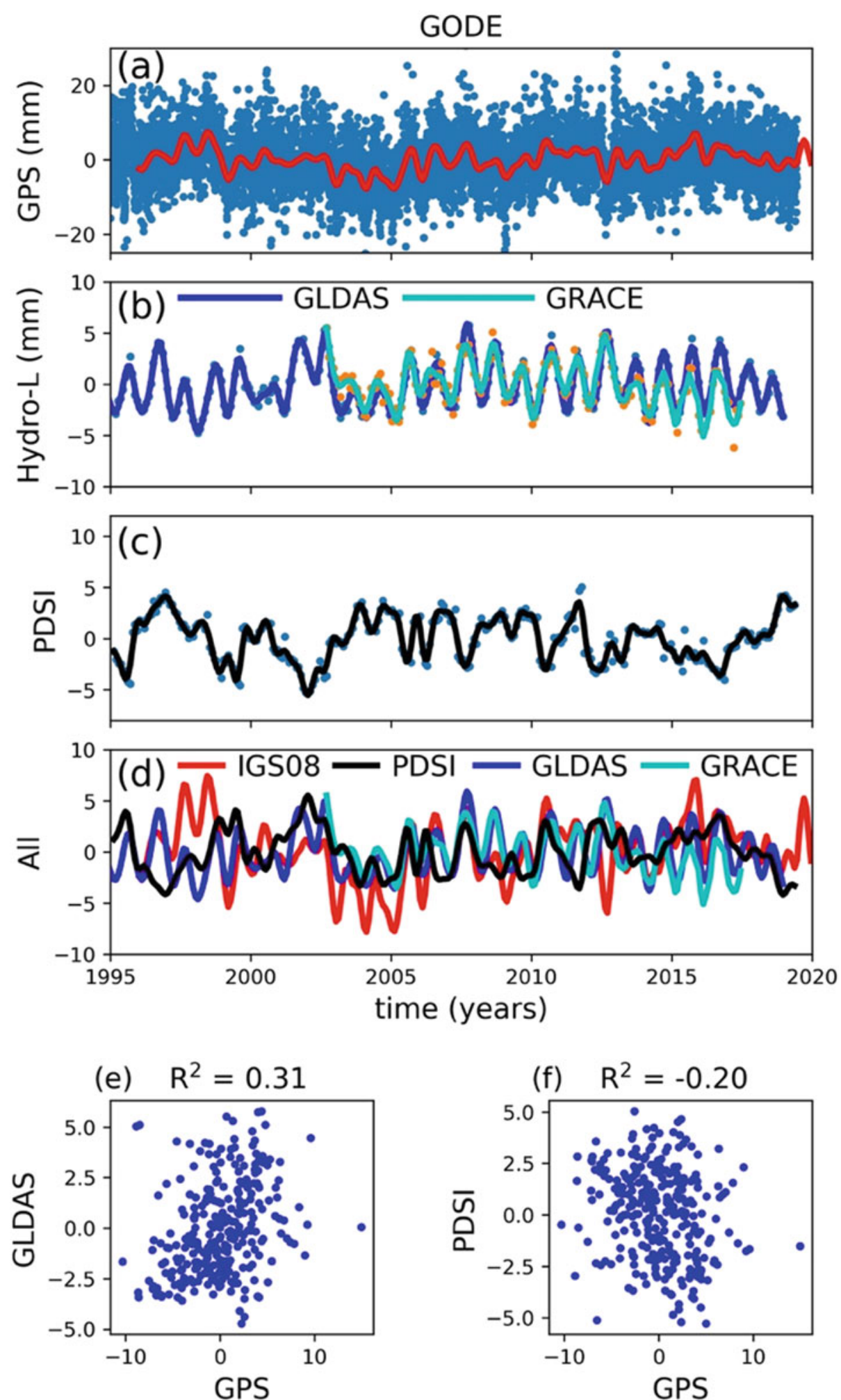

indicator of the hydrological load, which is used often for estimating Continental Water Storage (CWS). However, in some locations, as in GODE, the correlation between the observed GPS movements and predicted movements by hydrological loading changes yield poor correlations. The observed GPS movements, in such cases of poor correlation, represent most likely displacements in response to other physical processes, such as seasonal soil compaction or instability of the monument, which in many cases are located on buildings. These results suggest that vertical 
Fig. 5 Time series of vertical crustal movements and PDSI climate index for the site CCV5, located in central Florida.

Explanations for $(\mathbf{a}-\mathbf{f})$ as in Fig. 2


GPS time series cannot always serve as indicator for CWS. Furthermore, the results suggest that a correlation analysis between vertical GPS movements and predicted
GLDAS- or GRACE-based movements can serve as a useful tool for considering a GPS site for CWS estimates. 


\section{GPS-GRACE correlation $\left(R^{2}\right)$}

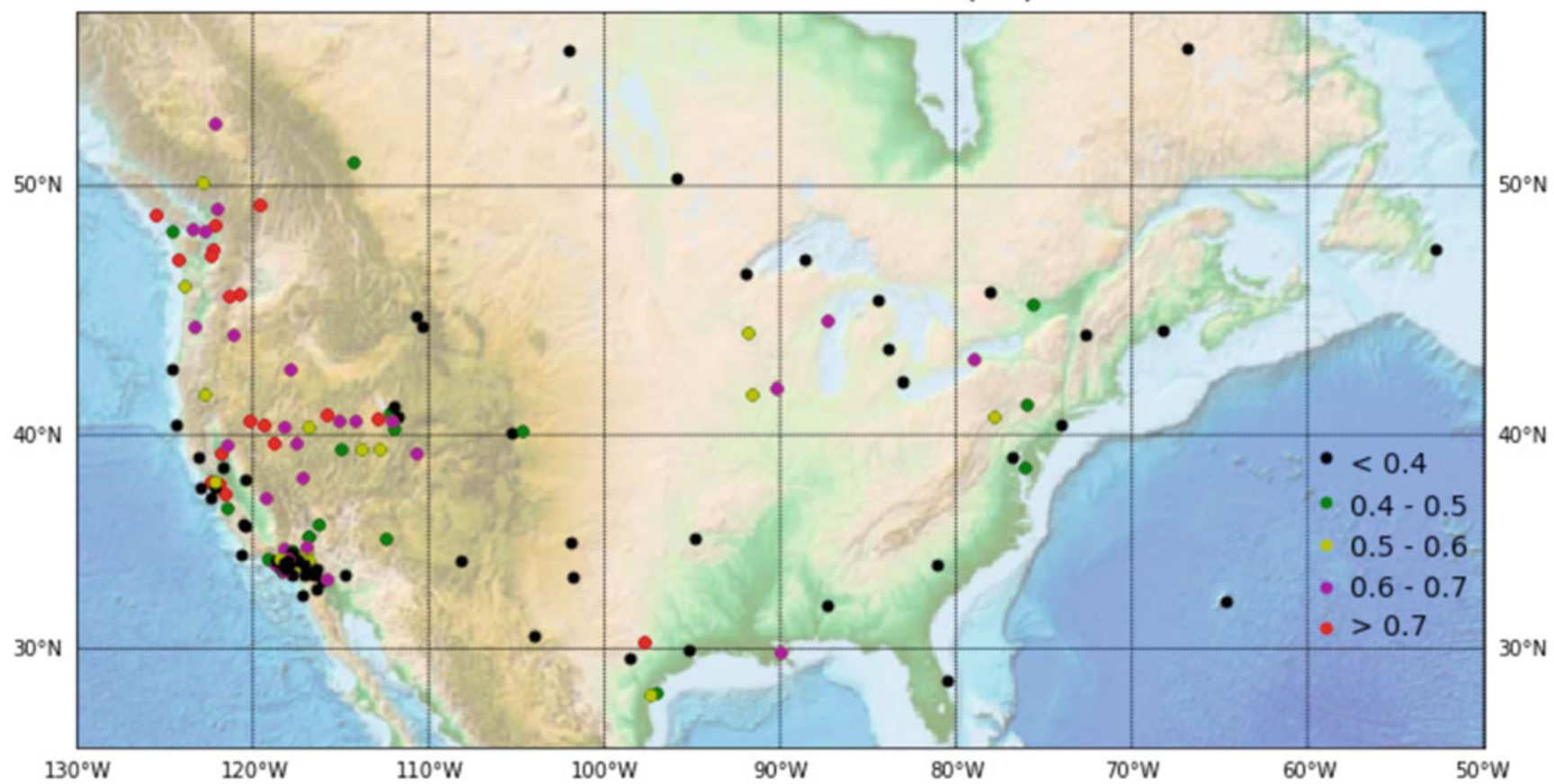

Fig. 6 Location map of GPS stations with long time series (>20 years). The color circles mark the correlation level between GPS and GRACEpredicted vertical movements

Acknowledgements The authors thank Paulo de Tarso Setti Júnior and Qiang Chen for data processing. This study was supported by NASA (Grant Number: 80NSSC17K0098).

\section{References}

Alley WM (1984) The Palmer drought severity index: limitations and assumptions. J Clim Appl Meteorol 23(7):1100-1109

Amos CB, Audet P, Hammond WC, Burgmann R, Johanson IA, Blewitt G (2014) Uplift and seismicity driven groundwater depletion in Central California. Nature 509(7501):483-486. https://doi.org/10. 1038/nature 13275

Bevis M, Wahr J, Khan SA, Madsen FB, Brown A, Willis M, Kendrick E, Knudsen P, Box JE, van Dam T (2012) Bedrock displacements in Greenland manifest ice mass variations, climate cycles and climate change. Proc Natl Acad Sci 109:11944-11948

Blewitt G, Kreemer C, Hammond WC, Goldfarb JM (2013) Terrestrial reference frame NA12 for crustal deformation studies in North America. J Geodyn 72:11-24

Brosa AA, Agnew DC, Cayan DR (2014) Ongoing drought-induced uplift in the western United State. Science 345(6204):1587-1590. https://doi.org/10.1126/science.1260279

Davis JL, Elósegui P, Mitrovica JX, Tamisiea ME (2004) Climatedriven deformation of the solid earth from GRACE and GPS. Geophys Res Lett 31(24):1-4

Farrell WE (1972) Deformation of the earth by surface loads. Rev Geophys 10(3):761-797. https://doi.org/10.1029/RG010i003p00761

Fu Y, Freymueller JT, Jensen T (2012) Seasonal hydrological loading in southern Alaska observed by GPS and GRACE. Geophys Res Lett 39(15): 15310
Hammond WC, Blewitt G, Kreemer C (2016) GPS imaging of vertical land motion in California and Nevada: implications for Sierra Nevada uplift. J Geophys Res Solid Earth 121(10):7681-7703

Jiang Y, Dixon TH, Wdowinski S (2010) Accelerating uplift in the North Atlantic region as an indicator of ice loss. Nat Geosci 3:404407

Mörner NA (1979) The Fennoscandian uplift and late Cenozoic geodynamics: geological evidence. GeoJournal 3(3):287-318

Rodell M et al (2004) The global land data assimilation system. Bull Am Meteorol Soc 85:381-394. https://doi.org/10.1175/BAMS-853-381

Swenson S, Wahr J (2006) Post-processing removal of correlated errors in GRACE data. Geophys Res Lett 33:L08402. https://doi.org/10. 1029/2005GL025285

Tregoning P, Watson C, Ramillien G, McQueen H, Zhang J (2009) Detecting hydrologic deformation using GRACE and GPS. Geophys Res Lett 36(15):L15401

van Dam T, Wahr J, Lavallée D (2007) A comparison of annual vertical crustal displacements from GPS and Gravity Recovery and Climate Experiment (GRACE) over Europe. J Geophys Res Solid Earth 112(B3):B03404

Wahr J, Khan SA, van Dam T, Liu L, van Angelen JH, van den Broeke MR, Meertens CM (2013) The use of GPS horizontals for loading studies, with applications to northern California and Southeast Greenland. J Geophys Res Solid Earth 118:1795-1806. https://doi.org/10.1002/jgrb.50104

Wdowinski S, Eriksson S (2009) Geodesy in the 21st century. Eos Trans AGU 90:153-155 
Open Access This chapter is licensed under the terms of the Creative Commons Attribution 4.0 International Licence (http://creativecommons.org/ licenses/by/4.0/), which permits use, sharing, adaptation, distribution and reproduction in any medium or format, as long as you give appropriate credit to the original author(s) and the source, provide a link to the Creative Commons licence and indicate if changes were made.

The images or other third party material in this chapter are included in the chapter's Creative Commons licence, unless indicated otherwise in a credit line to the material. If material is not included in the chapter's Creative Commons licence and your intended use is not permitted by statutory regulation or exceeds the permitted use, you will need to obtain permission directly from the copyright holder. 